Original Research Article

\title{
Clinical study of incidence of significant major aorto pulmonary collateral arteries in patients of TOF and its correlation with pulmonary artery anatomy
}

\author{
Doshi D ${ }^{1}$, Oswal N², Shukla $A^{3}$, Patel $P^{4}$, Shah $K^{5}$ \\ ${ }^{1}$ Dr. Dhaval Doshi, Assistant Professor, ${ }^{2}$ Dr. Nilesh Oswal, Assistant Professor, ${ }^{3}$ Dr. Anand Shukla, Professor, above all \\ authors are affiliated with Department of Cardiology, ${ }^{4}$ Ms. Priyanka Patel, Research Associate, Department of Research, \\ ${ }^{5}$ Dr. Komal Shah, Research Officer, Department of Research, all authors are affiliated with U N Mehta Institute of \\ Cardiology and Research Centre, Ahmedabad, Gujarat, India.
}

Address for Correspondence: Dr Dhaval Doshi, Assistant Professor of Cardiology, U N Mehta Institute of Cardiology and Research Centre, Ahmedabad, Gujarat, India, Email: drdoshidhaval@gmail.com

\begin{abstract}
Introduction: Tetralogy of Fallot (TOF) with hypoplastic pulmonary arteries and major aorto pulmonary collateral arteries (MAPCAs) is the most extreme variant of TOF. MAPCAs are frequently present and the main source of pulmonary flow in patients with TOF with hypoplastic arteries in the absence of patent ductus arteriosus (PDA). Objective: To study the incidence of significant MAPCAs in patients of TOF and its correlation with pulmonary artery anatomy. Patients and Methods: This prospective study has been conducted on a cohort of 100 consecutive TOF patients of 0-15 years of age. All the clinical and demographic parameters were collected. Two dimensional ECHO and CT pulmonary angiography was performed to define PA anatomy and MAPCAs morphology. Cardiac catheterization was performed as and when required. All the patients selected for the study, had PDA absent. Results: A total 56 patients had MAPCAs. Hypoplastic LPA was observed in 31 patients, of which $27(87 \%)$ had significant MAPCAs, and hypoplastic RPA was found in 46 patients with 40 (87\%) having significant MAPCAs. The mean diameter found was $5.78 \pm 3.52 \mathrm{~mm}$. Direct arborization pattern was observed in 45 patients. The mean oxygen saturation was $76.72 \pm 7$. Conclusion: Patients with TOF and hypoplastic pulmonary arteries had significant incidence of MAPCAs. The majority had MAPCAs with direct origin from descending aorta and larger diameter. A statistically significant difference was observed in the oxygen saturation levels in patients with and without MAPCAs.
\end{abstract}

Keywords: MAPCAs, Hypoplastic pulmonary arteries, TOF

\section{Introduction}

Tetralogy of Fallot (TOF) is the most common cyanotic congenital heart disease, with an incidence of approximately $0.33 / 1000$ live births making $6.8 \%$ of congenital heart lesions [1]. Tetralogy of Fallot with hypoplastic pulmonary arteries and aorto pulmonary collateral arteries is the most extreme variant of TOF. The arteries originating from the aorta or its branches supplying the pulmonary blood flow for a segment or a lobe of the lung without any connection to the central pulmonary arteries are defined as Major Aorto Pulmonary Collateral Arteries (MAPCAs). These aortopulmonary collateral arteries are frequently present

Manuscript received: $27^{\text {th }}$ January 2017

Reviewed: $7^{\text {th }}$ February 2017

Author Corrected: $15^{\text {th }}$ February 2017

Accepted for Publication: $21^{\text {st }}$ February 2017 and may supply partially or almost totally the pulmonary blood flow. These congenital systemic to pulmonary collateral arteries, are frequently the main source of pulmonary flow in patients with TOF with hypoplastic arteries either pulmonary atresia or severe pulmonary stenosis [2]. The central pulmonary artery in such patients are hypoplastic/complex morphology. In the presence of hypoplastic pulmonary arteries, the flow is dependent on the presence of MAPCAs in absence of PDA [3]. MAPCAs acts as compensatory mechanism and these usually arise from the descending aorta and subclavian arteries.

The pulmonary arteries are usually of a small caliber, often nonconfluent, and not connected to the right 
ventricle. In many cases, the proximal branches are stenotic, hypoplastic, or totally absent. Rabinovitch et al. described three distinct types of aortopulmonary collateral arteries, based on differences in histology and site of connection with pulmonary vascular bed: Bronchial arterial collaterals, direct systemic arterial collaterals, indirect systemic arterial collaterals [4]. All three major types of systemic arterial collaterals may be in Tetralogy of Fallot with pulmonary atresia, but only bronchial collaterals are present when Tetralogy occurs with pulmonary stenosis. Approximately $10 \%$ of arterial collaterals originate from coronary arteries.

In the current era, TOF is almost universally amenable to surgical repair with good long term outcome. This however, requires a thorough pre-operative anatomic description of central and branch pulmonary arteries and associated anamolies, like aortopulmonary collateral arteries, additional muscular VSD, ductus arteriosus and coronary artery anomalies for better surgical planning and outcome. We aim to define the incidence and implications of MAPCAs in patients with TOF and to correlate it with complex pulmonary artery morphology.

\section{Materials and Methods}

Patients and study design: This prospective study has been conducted on a cohort enrolled at a tertiary specialty center at Ahmedabad, Gujarat, India from the time period of July 2011 to June 2013. A total of 100 consecutive patients of TOF with hypoplastic pulmonary branches either pulmonary stenosis or atresia between the age group 0-15 years were enrolled for the study. Informed written consent was obtained from parents of each patient and approval of ethics committee was taken.

Diagnostic Parameters: All patients were thoroughly examined and evaluated for clinical parameters with a major focus on cyanosis and cyanotic spell. Oxygen saturation levels were measured using Pulse Oxymeter, as a non-invasive method for monitoring a patients oxygen saturation levels. Additional VSD, confluency and morphology of pulmonary artery branches, MAPCAs and other structural anomalies were evaluated by echocardiography. Computed Tomography pulmonary angiography was performed for the confirmation of pulmonary artery size and morphology, incidence of MAPCAs, site of origin, diameter, source and its arborization pattern. Pulmonary artery dimensions are presented as Z-scores adjusted for body surface area related to normal reference values published. Z-score of $[\leq(-2)]$ was used to define as hypoplastic and $[>(-2)]$ indicated fair size of the artery. Cardiac catheterization was performed as and when required. PDA was absent in all the patients enrolled for the study.

Statistical Analysis: Statistical analysis was performed using SPSS 22.0 software. Descriptive statistics for quantitative data included frequency (n), mean, standard deviation, 95\% confidence interval etc and qualitative data was defined in form of frequency/ percentage. Chisquare test/ Fisher's exact test (two-tailed, CI-0.05) were performed and p-value $<0.05$ was considered as significant. The Odds ratio was used to determine associations of LPA and RPA indexes, Z-scores with MAPCAs.

\section{Results}

During the study period from July'11 to June'14, a total of 100 patients having Tetralogy of Fallot (TOF) with hypoplastic pulmonary arteries either pulmonary stenosis or atresia were included in the study. Basic demographic and

Table-1: Baseline characteristics

\begin{tabular}{|c|c|}
\hline Variables & Number (\%)/ Mean \pm SD \\
\hline Total (n) & 100 \\
\hline Age Range (in years) & $0.2-15$ \\
\hline Age (Mean \pm SD) (in years) & $3.78 \pm 3.8$ \\
\hline Male & 57 \\
\hline Female & 43 \\
\hline LPA Z score [ $\leq(-2)]$ & 31 \\
\hline RPA Z score [ $\leq(-2)]$ & 46 \\
\hline MAPCAs present & 56 \\
\hline MAPCAs diameter (in mm) & $5.78 \pm 3.52$ \\
\hline Oxygen saturation (\%) & $76.72 \pm 7.0$ \\
\hline
\end{tabular}


clinical details are mentioned in Table 1. Mean age of the patients was $3.78 \pm 3.8$ years with 57 male and 43 females. Hypoplastic LPA was found in $31 \%$ and $46 \%$ patients had hypoplastic RPA. Fifty six patients had MAPCAs and the mean diameter found was $5.78 \pm 3.52 \mathrm{~mm}$; among these $45 \mathrm{had}$ direct arborization and the rest were of indirect origin. The mean oxygen saturation was $76.72 \pm 7$.

MAPCAs incidence and its correlation with hypoplastic/fair-size nature of pulmonary arteries by variation in Z-score is described in Table 2. Hypoplastic LPA was observed in 31 patients, out of which 27 (87\%) had significant MAPCAs, similarly, 46 patients had hypoplastic RPA with 40 (87\%) patients having significant MAPCAs. A total of 69 and 54 patients had fair sized LPA and RPA respectively. We found statistically significant association in patients with hypoplastic PA anatomy with the presence of MAPCAs $(\mathrm{p}<0.0001)$ as compared to fair sized PA anatomy.

Table-2: MAPCAs and its co-relation with PA anatomy.

\begin{tabular}{|c|c|c|}
\hline PA Z Score & APCAs Present & APCAs Absent \\
\hline LPA & & $4(13 \%)^{*}$ \\
\hline$[\leq(-\mathbf{2})] \mathbf{n}=\mathbf{3 1}$ & $27(87 \%)$ & $40(58 \%)^{*}$ \\
\hline$[>(-\mathbf{2})] \mathbf{n}=\mathbf{6 9}$ & $29(42 \%)$ & $6(13 \%)^{*}$ \\
\hline $\mathbf{R P A}$ & & $38(70.4 \%)^{*}$ \\
\hline$[\leq(-\mathbf{2})] \mathbf{n}=\mathbf{4 6}$ & $40(87 \%)$ & \\
\hline$[>(-\mathbf{2})] \mathbf{n}=\mathbf{5 4}$ & $16(29.6 \%)$ & \\
\hline
\end{tabular}

PA-Pulmonary Artery, Z score $[\leq(-2)]$ - Hypoplastic PA, Z score $[>(-2)]$ - Fair sized PA; $* \mathrm{p}<0.0001$

Hypoplastic nature in RPA $(31.89 ; 95 \%$ CI-10.608-95.889; $\mathrm{p}<0.0001)$ had higher Odds as compared to LPA (13.68; 95\% CI-4.586-40.83; $<<0.0001)$ as depicted in Table 3. Thus it can be concluded that hypoplastic RPA patients (OR-31.89) are more likely to develop MAPCAs as compared to the patients having fair-size RPA. Odds of hypoplastic LPA (OR13.68) patients is also high but as compared to RPA is low. One unit change in Z-score varied the outcome of developing MAPCAs by 13 to 30 times.

Table-3: Odds Ratio of pulmonary arteries and its association with MAPCAs.

\begin{tabular}{|c|c|c|c|c|}
\hline & Z score & Odds Ratio & \multicolumn{2}{|c|}{ 95\% CI } \\
\hline \multirow{3}{*}{ LPA } & & & Lower & Upper \\
\hline \multirow{2}{*}{ RPA } & {$[\leq(-2)]$} & $13.684^{*}$ & 4.586 & 40.830 \\
\cline { 2 - 5 } & {$[>(-2)]$} & $0.073^{*}$ & 0.024 & 0.218 \\
\cline { 2 - 5 } & {$[\leq(-2)]$} & $31.893^{*}$ & 10.608 & 95.889 \\
\hline
\end{tabular}

*-p<0.0001, LPA-Left Pulmonary Artery, RPA-Right Pulmonary Artery, CI-Confidence Interval

Table-4: MAPCAs and its correlation with origin and size.

\begin{tabular}{|c|c|c|c|c|}
\hline $\mathbf{Z}$ score $[\leq(-2)]$ & \multicolumn{2}{|c|}{ Origin } & \multicolumn{2}{c|}{ Diameter (in mm) } \\
\hline & Direct & Indirect & $\geq 3$ & $<3$ \\
\hline LPA & $20(74.1 \%)$ & $7(25.9 \%)^{*}$ & $19(70.3 \%)$ & $8(29.7 \%)^{*}$ \\
\hline RPA & $26(65 \%)$ & $14(35 \%)^{*}$ & $26(65 \%)$ & $14(35 \%)^{*}$ \\
\hline
\end{tabular}

*-p<0.0001, LPA-Left Pulmonary Artery, RPA-Right Pulmonary Artery.

Table 4 displayed the correlation between direct/indirect origin, size (diameter, in mm) and PA anatomy. MAPCAs of direct origin was found in $20(74.1 \%)$ and $26(65 \%)$ in hypoplastic LPA and RPA respectively. Seven patients with hypoplastic LPA (25.9\%) had MAPCAs that originated from other aortic branches (i.e. sub clavian artery, arch of aorta, ascending aorta etc.). Similarly, 14 (35\%) patients had indirect origin in hypoplastic RPA. Directly originating MAPCAs 
from descending thoracic aorta were correlated significantly to hypoplastic PA branches with $\mathrm{p}<0.001$. Mean diameter of MAPCAs was found as $5.78 \pm 8.52$. Majority of patients with hypoplastic LPA and RPA had significantly large diameter of MAPCAs $(\geq 3 \mathrm{~mm}, \mathrm{p}<0.001)$ as compared to fair sized pulmonary arteries.

Table-5: MAPCAS and its correlation with Oxygen saturation.

\begin{tabular}{|c|c|c|c|c|}
\hline MAPCAs & $<\mathbf{7 0 \%}$ & $\mathbf{7 0 - 8 0} \%$ & $\mathbf{> 8 0} \%$ & p-value \\
\hline & $\mathrm{n}=27$ & $\mathrm{n}=45$ & $\mathrm{n}=28$ & \\
\hline Present & $6(22.2 \%)$ & $29(64.4 \%)$ & $21(75 \%)$ & 0.0062 \\
\hline Absent & $21(77.8 \%)$ & $16(35.5 \%)$ & $7(25 \%)$ & \\
\hline
\end{tabular}

Table 5 describes the association between MAPCAs and oxygen saturation. Maximum number of patients having MAPCAs had oxygen saturation of $>80 \%$ [21 (75\%)] and only a few [6 (22.2\%)] had saturation levels of $<70 \%$, while the patients without MAPCAs had lower (<70\%) oxygen saturation levels (saturation level $<70 \%, 21(77.8 \%)$ vs saturation level $>80 \%, 7(25 \%))$. Oxygen saturation had significant positive association with MAPCAs incidence (0.0068).

\section{Discussion}

The arteries originating from the aorta or its branches supplying the pulmonary blood flow for a segment or a lobe of the lung without any connection to the central pulmonary arteries are defined as Major Aortopulmonary Collateral Arteries (MAPCAs).

These are large, congenital, systemic-to-pulmonary collateral arteries, representing remnants of the embryonic ventral splanchnic arteries [5]. Over the last decades investigators have gained great insight into the relationship of MAPCAs to the development of conotruncal heart defects. Cho et al. (2002) reported that the presence of MAPCAs was a significant factor associated with late mortality $(\mathrm{p}=0.0182)$ [6].

They are majorly classified into type I - bronchial artery branch, type II - direct aortic branch, type III - indirect aortic branch $[4,7]$. The blood supply in a condition of hypoplastic pulmonary artery condition is primarily dependent on the presence of the aortopulmonary collateral channels in absence of PDA.

Pulmonary blood supply is widely variable in patients affected and hence, diagnosis and management of TOF with hypoplastic pulmonary branches is more difficult [8]. Also the degree of clinical symptoms presented depends on the extent of stenosis of the PA branches.

Diminished pulmonary blood flow appears to result in poor growth of peripheral pulmonary arteries [4]. In general most large series including our own have found that MAPCAs are present in $40-50 \%$ of TOF subjects with hypoplastic pulmonary arteries either pulmonary stenosis or atresia. [8, 9].
Majority of our patients with TOF having hypoplastic PA branches $(\mathrm{z}$-score $\leq(-2))$ notwithstanding required pulmonary blood supply significantly developed MAPCAs $(p=<0.0001)$. The incidence of MAPCAs in patients with hypoplastic PA branches was significantly higher than compared to fair sized LPA and/ or RPA.

The place of origin, course, and branching pattern of the major aortopulmonary collaterals, as well as the size of the pulmonary arteries, may vary because of the exact timing and degree of mal-development that occurs in the pulmonary outflow tract [5]. Direct systemic arterial collaterals that originate from descending aorta, enter the hilum and then assume the structure and distribution of intrapulmonary arteries. Indirect systemic arterial collaterals that originate from major aortic branches other than bronchial arteries (internal mammary, innominate, subclavian) and anastomose to proximal pulmonary arteries outside the lung [4].

We observed MAPCAs originating directly from descending aorta along with a diameter of $\geq 3 \mathrm{~mm}$ in majority of patients with an indication to counterbalance the decreased pulmonary blood supply due to hypoplastic nature of PA branches. The diameter of MAPCAs significantly correlates with hypoplastic nature of PA branches and compensates the arterial blood supply. Mean diameter of MAPCAs as large as 5 $\mathrm{mm}$ have also been reported [10]. It has been widely accepted that MAPCAs, which seemingly freely perfuse lung segment and may improve arterial oxygen saturation along with pulmonary hypertension in these segments [4, 11, 12]. In our study cohort, we have observed increased oxygen saturation levels in the 
patients having MAPCAs. A majority of patients of the study cohort with $>80 \%$ of oxygen saturation levels had higher incidence of MAPCAs, which might be considered to be helpful in survival in these patients which was also statistically significant $(p<0.05)$. This implies that most patients with hypoplastic pulmonary artery branches significantly had MAPCAs with direct origin $(\mathrm{p}<0.001)$ as compared to those originating indirectly from aortic branches other than bronchial arteries as supported by earlier evidence [7, 10, 13-15].

Some researchers have reported that number of MAPCAs increases with age and significantly benefit in survival by maintenance of additional blood supply in the body [16]. On the basis of these results, we would like to suggest a direct relationship in patients of TOF with pulmonary atresia/ pulmonary stenosis between the incidence, origin and size of MAPCAs and the hypoplastic nature of PA branches.

Management strategies in patients of TOF mainly depends on anatomic description of central and branch pulmonary arteries and associated anomalies, like major aortopulmonary collateral arteries.

\section{Conclusion}

Patients with TOF with hypoplastic branches had significantly higher incidence of MAPCAs. Hypoplastic RPA had higher Odds as compared to hypoplastic LPA. Majority of patients had MAPCAs having direct origin and a larger diameter. The oxygen saturation levels were also higher as compared.

$\begin{array}{ll}\text { Abbreviations } & \\ \text { TOF } & \text { Tetralogy of Fallot } \\ \text { MAPCAs } & \text { Major Aorto Pulmonary Collateral Arteries } \\ \text { VSD } & \text { Ventricular Septal Defect } \\ \text { PA } & \text { Pulmonary Artery } \\ \text { RPA } & \text { Right Pulmonary Artery } \\ \text { LPA } & \text { Left Pulmonary Artery } \\ \text { MPA } & \text { Main Pulmonary Artery } \\ \text { DTA } & \text { Descending Thoracic Aorta } \\ \text { LAD } & \text { Left Anterior Descending Artery } \\ \text { LCx } & \text { Left Circumflex artery } \\ \text { RCA } & \text { Right Coronary Artery } \\ \text { PDA } & \text { Patent Ductus Arteriosus } \\ \text { ASD } & \text { Atrial Septal Defect }\end{array}$

Funding: Nil, Conflict of interest: None initiated, Perission from IRB: Yes

\section{References}

1. Moss \& Adams' Heart Disease in Infants, Children, and Adolescents: Including the Fetus and Young Adults.

2. Moll JN, Santos MA, Drumond C, Romao NO, Murad M, Reis NB. Improved visualization of aortopulmonary collateral arteries by abdominal aortic compression during angiography. Circulation. 1982 May 1;65(5):953-5. DOI: https://doi.org/10.1161/01. CIR. 65.5.953

3. Somerville J. Management of pulmonary atresia. British heart journal. 1970 Sep 1; 32 (5):641-51. DOI: http://dx.doi.org/10.1136/hrt.32.5.641

4. Rabinovitch MA, Herrera-deLeon VI, Castaneda AR, Reid L. Growth and development of the pulmonary vascular bed in patients with tetralogy of Fallot with or without pulmonary atresia. Circulation. 1981 Dec 1;64 (6):1234-49.

5. Boshoff D, Gewillig M. A review of the options for treatment of major aortopulmonary collateral arteries in the setting of tetralogy of Fallot with pulmonary atresia. Cardiology in the Young. 2006 Jun 1;16(03):212-20. DOI: https://doi.org/10.1017/S1047951106000606.

6. Cho JM, Puga FJ, Danielson GK, Dearani JA, Mair DD, Hagler DJ, et al. Early and long-term results of the surgical treatment of tetralogy of Fallot with pulmonary atresia, with or without major aortopulmonary collateral arteries. The Journal of Thoracic and Cardiovascular Surgery. 2002 Jul 31;124(1):70-81. DOI: 10.1067/mtc. 2002.120711

7. Chessa M, Butera $\mathrm{G}$, Bonhoeffer $\mathrm{P}$, Iserin $\mathrm{L}$, Kachaner J, Lyonnet S, Munnich A, Sidi D, Bonnet D. Relation of genotype 22q11 deletion to phenotype of pulmonary vessels in tetralogy of Fallot and pulmonary atresia-ventricular septal defect. Heart. 1998 Feb 1; 79 (2):186-90.DOI: http://dx.doi.org/10.1136/hrt. 79.2.186.

8. Yoo SJ, Moes CF, Burrows PE, Molossi S, Freedom RM. Pulmonary blood supply by a branch from the distal ascending aorta in pulmonary atresia with ventricular septal defect: differential diagnosis of fifth aortic arch. Pediatric cardiology. 1993 Oct 1;14(4):2303. DOI: 10.1007/BF00795377. 
9. Somerville J, Saravalli O, Ross D. Complex pulmonary atresia with congenital systemic collaterals. Classification and management. Archives des maladies du coeur et des vaisseaux. 1978 Mar; 71(3): 322-8. PMID: 416806.

10. Mahle WT, Crisalli J, Coleman K, Campbell RM, Tam VK, Vincent RN, Kanter KR. Deletion of chromosome 22q11. 2 and outcome in patients with pulmonary atresia and ventricular septal defect. The Annals of thoracic surgery. 2003 Aug 31;76(2):567-71. DOI:http://dx.doi.org/10.1016/S0003-4975(03)00516-2.

11. Leonard H, Derrick G, O'sullivan J, Wren C. Natural and unnatural history of pulmonary atresia. Heart. 2000 Nov 1;84(5):499-503. DOI: http://dx.doi. org /10.1136/ heart.84.5.499.

12. Hofbeck M, Rauch A, Buheitel G, Leipold G, von der Emde J, Pfeiffer R, Singer H. Monosomy 22q11 in patients with pulmonary atresia, ventricular septal defect, and major aortopulmonary collateral arteries. Heart. 1998 Feb 1; 79 (2):180-5. DOI: http://dx.doi. org/10. 1136/hrt.79.2.180.

13. Marino B, Digilio MC, Grazioli S, Formigari R, Mingarelli R, Giannotti A, Dallapiccola B. Associated cardiac anomalies in isolated and syndromic patients with tetralogy of Fallot. The American journal of cardiology. 1996 Mar 1;77(7):505-8. DOI: http://dx.doi. org/10. 1016/ S0002-9149(97)89345-9.

14. Momma K, Kondo C, Matsuoka R. Tetralogy of Fallot with pulmonary atresia associated with chromosome 22q11 deletion. Journal of the American College of Cardiology. 1996 Jan 1;27(1):198-202. DOI: http://dx. doi. org /10. 1016/ 0735- 1097 (95) 00415-7.

15. Uflacker R, Kaemmerer A, Picon PD, Rizzon CF, Neves CM, Oliveira ES, Oliveira ME, Azevedo SN, Ossanai R. Bronchial artery embolization in the management of hemoptysis: technical aspects and longterm results. Radiology. 1985 Dec;157(3):637-44. DOI: http://dx. doi. org /10. 1148/ radiology. 157. 3. 4059552

16. Reddy VM, McElhinney DB, Amin Z, Moore P, Parry AJ, Teitel DF, Hanley FL. Early and intermediate outcomes after repair of pulmonary atresia with ventricular septal defect and major aortopulmonary collateral arteries. Circulation. 2000 Apr 18; 101(15): 1826-32. DOI: http: //doi.org/10. 1161/01. CIR. 101. 15.1826 .

\section{How to cite this article?}

Doshi D, Oswal N, Shukla A, Patel P, Shah K. Clinical study of incidence of significant major aorto pulmonary collateral arteries in patients of TOF and its correlation with pulmonary artery anatomy. J PediatrRes.2017;4(02):100105.doi:10.17511/ijpr.2017.i02.02. 